\title{
川东南杂交中稻超稀栽培对稻米整精米率 和严白粒率的影响
}

\author{
徐富贤 ${ }^{1}$ 郑家奎 ${ }^{*} \quad$ 朱永川 $^{1}$ 王贵雄 $^{1}$ 杨大金 $^{2}$ 刘 康 $^{2}$ \\ （1 四川省农业科学院水稻高粱研究所, 泸州 646000）（2 泸州市农业局, 泸州 646000）
}

\begin{abstract}
摘 要 以 II 优 7 号' ‘ 汕优 $63^{\prime}$ 和 香优 2 号' 为材料, 研究了超稀栽培与稻米整精米率和亚白粒率的关系及其作 用原因 结果表明 栽种密度与整精米率呈极显著负相关, 与严白粒率呈极显著正相关。在中高氮施肥水平条件 下, 当栽秧密度超稀到 7.51 万穴 $\mathrm{hm}^{-2}$ 时，在保证比传统高产栽培密度每公顷栽秧 21.64 万穴的对照不减产前提 下, 整精米率提高了 $15.69 \%$ 29.92\% 严白粒率降低了 $16.34 \% ２ 1.22 \%$ 。其原因在于, 超稀植增加了每穗着粒 数, 降低了齐穗期的叶粒比, 以致稻穗籽粒灌浆速率减慢而改善整精米率和严白粒率。齐穗后 $20 \mathrm{~d}$ 施氮可同时起 到提高结实率和整精米率的双重效果。
\end{abstract}

关键词 杂交中稻 超稀植 整精米率 严白粒率

\section{EFFECT OF SUPER SPARSE CULTIVATION ON HEAD MILLED RICE PERCENTAGE AND CHALKINESS IN HYBRID RICE VARIETIES IN THE EASTERN AND SOUTHERN DISTRICTS OF SICHUAN PROVINCE}

\author{
XU Fu-Xian ${ }^{1}$ ZHENG Jia-Kui ${ }^{1}$ ZHU Yong-Chuan ${ }^{1}$ WANG Gui-Xiong ${ }^{1}$ Yang Da-Jin ${ }^{2}$ LIU Kang ${ }^{2}$ \\ (1 Rice and Sorghum Institute, Sichuan Academy of Agricultural Sciences , Luzhou 646000 , China) \\ (2 Luzhou Municipal Burean of Agriculture , Luzhou 646000 , China)
}

\begin{abstract}
In the eastern and southern districts of Sichuan Province, grain yields of hybrid midseason-rice varieties have been increased, but its grain quality remains very poor. In particular, the head rice percentage is low and chalkiness is high due to high air temperatures that occur 0 to 20 days after full heading. Although many studies have examined the effects of cultivation factors on grain quality , few improvements in grain quality have been made in these special districts. This paper explores the effect of super sparse cultivation on head rice recovery and chalkiness in hybrid rice varieties and provides a theoretical and practical basis for the cultivation of high quality rice. The experimental design consisted of three hybrid rice varieties '( II you 7' , 'Shanyou 63' and Xiangyou 2' ) planted at six different densities, where the hill was removed at full heading and $\mathrm{N}$ applied on different days after full heading in a randomized block design with $3 \sim 4$ replications. Using analysis of variance and correlation analysis, the results indicated that there were highly significant negative correlations between planting density and the percentage of head milled rice and highly significantly positive correlations between plant seedling density and the chalky percent. When super sparse cultivation was at 7.51 $\times 10^{4}$ hill $\mathrm{hm}^{-2}$ with $150-210 \mathrm{~kg} \mathrm{~N} \mathrm{hm}^{-2}$, the grain yield was equal to CK $\left(21.64 \times 10^{4}\right.$ hill per $\mathrm{hm}^{2}$ with $150 \mathrm{~kg} \mathrm{~N} \mathrm{hm}^{-2}$ ), but the percentage of head milled rice increased by $15.69 \%$ to $22.92 \%$, and the chalky percent decreased by $16.34 \%$ to $21.22 \%$. The increase in grain quality in super sparse cultivation was due to an increase in the number of spikelets per panicle, a decrease in the weight of leaf per grain at full heading , and reduced grain filling rate ; hence, the percentage of head milled rice and chalkiness were improved. Additionally , the seed setting rate and the percentage of head milled rice in super sparse cultivation were increased by applying $\mathrm{N} 20$ days after full heading.
\end{abstract}

Key words Hybrid mid-season rice , Super sparse cultivation , Percentage of head milled rice , Percentage of chalky rice

虽然目前杂交中稻产量已经达到较高水平，但 其碾米品质和外观品质普遍表现较差 (廖伏明等， 1999)。稻米品质除了受品种自身遗传基因的控制
外,在很大程度上还受环境条件的影响(徐富贤等， 1994)。特别是川东南高温伏旱区 现有稻田 150 多 万公顷 (含重庆市)，其中杂交中籼迟熟品种(组合) 
种植面积占 $90 \%$ 以上。由于规律性的 7 月上中旬 至 8 月中下旬的自然高温,促使杂交中稻稻谷高温 逼熟, 以致本来稻米品质就差的杂交中稻则变得更 劣。如我们 2000 年对四川省 9 个育种单位提供的 基本反映四川省优质杂交稻育种现状的 59 个优质 杂交中稻稻米品质的测定结果为: 整精米率、严白粒 率、严白度变幅分别为 $20.06 \% \sim 56.40 \% 、 23 \% ～$ $79 \%$ 和 $4.30 \% \sim 48.24 \%$, 其中达国家三级优质稻谷 标准的组合数分别仅占 $9.56 \% 、 8.28 \%$ 和 $5.69 \%$ （朱永川等，2000；国家质量技术监督局，1999），表明 整精米率和严白性状是川东南高温伏旱区杂交中稻 优质育种急需改良的重要品质性状之一。

关于栽培措施对稻米品质的影响国内外已有较 多研究, 多数学者认为水稻稀植, N、K 配合施用, 后 期推迟排水, 完熟期收割有利于提高米质(徐富贤 等,1994 杨泽敏等,2001; 徐富贤等,2003a）,但其米 质的提高程度并非十分理想。如我们 2000 年对 菲 优 1 号' 的优质高产栽培研究结果表明,在高产前提 下，优质栽培措施的整精米率仅提高了 $5.2 \%$, 严白 粒率仅降低了 $4.8 \%$ (徐富贤等, 2003b)。我们在 2001 年进行水稻强化栽培研究时,无意中发现杂交 中稻强化栽培处理 (每平方公顷栽 4 万穴) 比对照 (每平方公顷栽 22.5 万穴) 的整精米率和严白粒率 有大幅度的改善。鉴于此, 我们于 2002 年对杂交中 稻超稀栽培与整精米率和严白粒率的关系及其作用 机理进行了系统研究, 以期为川东南高温伏旱区杂 交中稻优质栽培技术研究提供理论和实践依据。

\section{1 材料和方法}

试验在四川省农业科学院水稻高粱研究所实验 场的冬水田进行, 供试土质均匀, 中上等肥力, 试验 处理以外的其它栽培管理均同大田生产。

1.1 试验一本田栽秧密度与稻谷产量及其整精米 率和严白粒率的关系研究

试验设计 次迟熟杂交中稻组合 II 优 7 号'为 材料，3月 8 日播种，地膜水育中苗秩，4 叶左右移 栽。施氮量分别为每公顷施纯 N $195 \mathrm{~kg}$ (高氮) 和每 公顷施纯 N $120 \mathrm{~kg}$ (中氮) 两个水平, 其中底肥 $70 \%$,追肥 $30 \%$ 。栽秧密度分别为 $4.83 、 7.51$ 、 $10.76 、 14.80 、 18.91 、 21.64$ 万穴 $\mathrm{hm}^{-2} 6$ 个水平, 每穴 栽单株。两因素共 12 个处理。每个处理小区种植 面积 $13.35 \mathrm{~m}^{2}$,重复 3 次, 顺序排列。区间(间距均 为 $80 \mathrm{~cm}$ ) 扎双埂, 并用塑料薄膜包扎。

考查项目 :1) 按常规方法考查各处理的最高苗
数和有效穗数, 并计算成穗率 $(\%)$ 。2) 齐穗期各处 理每次重复按其小区平均有效茎数取样 3 穴, 采用 干物重法考查叶粒比 (即单位颖花占有的绿叶干物 质重量 $=$ 取样植株绿叶总干物质重量 $\div$ 取样植株稻 穗的总颖花数 $\mathrm{mg}$ 粒 $\left.{ }^{-1}\right)$ 和库容量 $\left(\right.$ 万粒 $\left.\mathrm{m}^{-2}\right)$ 。3) 齐穗期各组合每次重复选择生长基本一致的 35 44 个稻穗挂牌标记, 用以测定齐穗后 $0 \sim 20 \mathrm{~d}$ ( 因稻 米外观品质主要受齐穗后 $0 \sim 20 \mathrm{~d}$ 灌浆速率的影 响)(徐富贤等,2003b) 稻穗中部籽粒的日平均灌浆 速率 $\left(m g\right.$ 粒 $\left.{ }^{-1} d^{-1}\right)$ 。4) 成熟期用排水法测定各组 合每次重复稻谷饱满籽粒的容重 $(\mathrm{mg} \mathrm{ml})^{-1}$ ) (徐富 贤等,2003b)。5)成熟期各处理的每次重复按其小 区平均有效茎数取样 3 穴, 考查穗部性状并收实产。 6) 水稻收获后 3 个月, 将各组合 3 次重复的稻谷取 样混匀, 按国家质量技术监督局 (1999) 发布的主要 粮食质量新国家标准测定稻谷整精米率 $(\%)$ 和严白 粒率 $(\%)$ 。

统计分析 :首先对小区实产、整精米率和严白粒 率进行方差分析, 然后利用各处理 3 次重复的平均 值，进行主要性状间的相关与回归分析(胡秉民等， 1985)。

1.2 试验二 : 齐穗期叶粒比与透光率对整精米率和 严白粒率的影响研究

试验设计 : 以迟熟杂交中稻组合 汕优 63' 和 香优 2 号' 为材料, 3 月 10 日播种, 地膜水育中苗 积 $A$ 叶左右移栽, 每穴栽单株。本田每公顷施纯氮 $150 \mathrm{~kg}$ (其中底肥 $70 \%$, 追肥 $30 \%$ ) 磷钾肥按 $\mathrm{N}: \mathrm{P}: \mathrm{K}$ $=1: 0.5: 0.5$ 的量作底肥。设 $I$ :每公顷栽 9 万穴, II 每公顷栽 18 万穴, 齐穗期疏穴为 9 万穴 $\mathrm{hm}^{-2}$, III :CK ,每公顷栽 18 万穴共 3 处处理, 每个处理小区 种植面积 $13.35 \mathrm{~m}^{2}$, 重复 4 次, 顺序排列, 区间走道 $35 \mathrm{~cm}$ 。

考查项目: 1) 齐穗期用国产 2D-II 型照度计测定 所有试验小区穗层和植株基部(靠茎秆距地面 $10 \mathrm{~cm}$ 处)的光照度, 每小区重复 4 次, 并以 4 次重复的平 均值计算透光率 $(\%)$ 。2)按试验一的方法考查齐穗 期各处理每次重复的叶粒比 ( $\mathrm{mg}$ 粒 $\left.{ }^{-1}\right)$ 、整精米率 $(\%)$ 和严白粒率 $(\%)$ 。

统计分析: 分别进行各处理间透光率 $(\%)$ 、叶粒 比 ( $\mathrm{mg}$ 粒 $\left.^{-1}\right)$ 、整精米率 $(\%)$ 和严白粒率 $(\%)$ 的方 差分析(胡秉民等,1985)。

1.3 试验三 :齐穗后不同时期施氮对结实率、整精 米率等性状的影响研究

试验设计 : 以迟熟杂交中稻组合 汕优 63' 和 
香优 2 号” 为材料, 3 月 10 日播种, 地膜水育中苗 积, 4 叶左右移栽, 按每公顷栽 9 万穴的规格每穴栽 单株。本田每公顷施纯氮 $150 \mathrm{~kg}$ (其中底肥 $70 \%$, 追肥 $30 \%$ ）磷钾肥按 $\mathrm{N}: \mathrm{P}: \mathrm{K}=1: 0.5: 0.5$ 的量作底 肥。设齐穗后 $0 、 10 、 20 、 30 \mathrm{~d}$ 分别施纯氮 $34.5 \mathrm{~kg}$ $\mathrm{hm}^{-2}$ 和 CK(不施肥) 5 个处理, 每个处理小区种植面 积 $13.35 \mathrm{~m}^{2}$,重复 3 次, 顺序排列，区间扎双埂(间 距均为 $80 \mathrm{~cm})$,并用塑料薄膜包扎。

考查项目 :按前试验方法考查各处理每次重复 的结实率 $(\%)$ 、千粒重 $(\mathrm{g})$ 、小区实产 $\left(\mathrm{t} \mathrm{hm} \mathrm{hm}^{-2}\right)$ 整精 米率 $(\%)$ 和严白粒率 $(\%)$ 。

统计分析: 分别进行各处理间结实率 $(\%)$ 、千粒 重 $(\mathrm{g})$ 、小区实产 $\left(\mathrm{t} \mathrm{hm}{ }^{-2}\right)$ 、整精米率 $(\%)$ 和严白粒 率 $(\%)$ 的方差分析(胡秉民等 ,1985)。

\section{2 结果与分析}

2.1 超稀栽培与产量、整精米率和严白粒率的关系

从试验结果表 1 可见,在每公顷栽秧 4.83 21.64 万穴范围内 本田栽秧密度对稻谷产量及其整 精米率和严白粒率均有显著影响, 其中本田栽秧密 度与整精米率呈极显著负相关，与王白粒率呈极显 著正相关, 与产量的相关性未达显著水平 ,中氮和高 氮两种施肥水平的表现趋势一致。

就不同施氮水平间的差异来看,在相同栽秩密 度条件下, 高氮与中氮两种施肥水平间的产量和整 精米率均有显著差异, 严白粒率间的差异不显著。 其中 : 1)对产量的影响，以传统高产栽培密度每公顷 栽秩 21.64 万穴为对照 (后同) ,中氮施肥条件下, 每 公顷栽秩 $10.76 \sim 18.91$ 万穴比对照显著增产; 高氮 施肥条件下, 每公顷栽秧 $7.51 \sim 18.91$ 万穴比对照
显著增产，以每公顷栽秧 $7.51 \sim 10.76$ 万穴的产量 较高。2)对整精米率的影响, 中氮和高氮施肥条件 下, 每公顷栽秧密度 $4.83 \sim 18.91$ 万穴范围内均比 对照显著提高, 中氮以每公顷栽秩 $4.83 \sim 10.76$ 万 穴的较高, 高氮以每公顷栽秧 $4.83 \sim 7.51$ 万穴的较 高。3)对严白粒率的影响，中氮和高氮施肥条件下， 每公顷栽秧密度 $4.83 \sim 14.8$ 万穴范围内均比对照 显著降低, 中氮以每公顷栽种 4.83 万穴的最低, 高 氮以每公顷栽秧 $4.83 \sim 7.51$ 万穴的较低。

综上所述，无论是中氮还是高氮施肥水平，当栽 秧密度超稀到 7.51 万穴 $\mathrm{hm}^{-2}$ 时, 在保证比传统高 产栽培密度每公顷栽秧 21.64 万穴的对照不减产前 提下, 整精米率提高了 $15.69 \% \sim 29.92 \%$ 严白粒率 降低了 $16.34 \% \sim 21.22 \%$ 。表明水稻超稀植具有十 分显著地提高整精米率和降低严白粒率的效应。

2.2 水稻超稀植影响整精米率和严白粒率的作用 因素分析

\subsection{1 栽秧密度与水稻植株性状的关系}

从试验结果表 2 看出,除了栽秧密度与千粒重 和库容量二性状没有显著相关外, 对其它性状均有 明显影响。主要表现为随着栽秧密度的变稀, 有效 穗数减少, 成穗率提高, 着粒数增加, 结实率和叶粒 比降低，灌浆速率减慢，籽粒容重增加。以上结果在 高氮和中氮两种施肥水平条件下均表现一致。此 外, 因稀植的灌浆速率减慢, 灌浆期相应延长, 如 7.51 万穴 $\mathrm{hm}^{-2}$ 处理的生育期延长了 $3 \mathrm{~d}$ 左右。

2.2.2 水稻超稀植显著提高整精米率和降低严白 粒率的原因

水稻稀植既提高了齐穗期群体透光率 (栽秧密 度与齐穗期透光率呈极显著负相关, 相关系数为

表 1 栽秧密度对稻谷产量及其整精米率和严白粒率的影响

Table 1 Effect of plant seedling density on grain yield and its percentage of head milled rice and percentage of chalky rice

\begin{tabular}{|c|c|c|c|c|c|c|}
\hline \multirow{2}{*}{$\begin{array}{l}\text { 栽培密度 } P S D \\
\left(10^{4} \mathrm{hill}^{-2} \mathrm{hm}^{-2}\right)\end{array}$} & \multicolumn{2}{|c|}{ 产量 Grain yield $\left(\mathrm{t} \mathrm{hm}^{-2}\right)$} & \multicolumn{2}{|c|}{ 整精米率 PHMR (\%) } & \multicolumn{2}{|c|}{ 垔白粒率 PCR $(\%)$} \\
\hline & 中氮量 M-N & 高氮量 H-N & 中氮量 M-N & 高氮量 H-N & 中氮量 M-N & 高氮量 H-N \\
\hline 4.83 & $7.03^{\mathrm{Bd}}$ & $7.49^{\mathrm{Ad}}$ & $50.24^{\mathrm{Ba}}$ & $55.88^{\mathrm{Aa}}$ & $29.96^{\mathrm{Ad}}$ & $28.67^{\mathrm{Ad}}$ \\
\hline 7.51 & $8.29^{\mathrm{Bbc}}$ & $8.65^{\text {Aab }}$ & $47.18^{\text {Bab }}$ & $54.27^{\mathrm{Aa}}$ & $36.33^{\mathrm{Ac}}$ & $34.63^{\mathrm{Ad}}$ \\
\hline 10.76 & $8.42^{\text {Bab }}$ & $8.81^{\mathrm{Aa}}$ & $44.76^{\text {Aab }}$ & $41.01^{\mathrm{Ab}}$ & $40.32^{\mathrm{Ac}}$ & $42.33^{\mathrm{Ac}}$ \\
\hline 14.80 & $8.66^{\mathrm{Aa}}$ & $8.26^{\mathrm{Ab}}$ & $43.02^{\mathrm{Abc}}$ & $38.80^{\mathrm{Abc}}$ & $43.35^{\mathrm{Abc}}$ & $47.67^{\mathrm{Abc}}$ \\
\hline 18.91 & $8.72^{\mathrm{Aa}}$ & $7.99^{\mathrm{Bc}}$ & $37.87^{\mathrm{Ad}}$ & $31.03^{\mathrm{Bbd}}$ & $48.39^{\text {Aab }}$ & $51.66^{\text {Aab }}$ \\
\hline $21.64(\mathrm{CK})$ & $8.06^{\mathrm{Ac}}$ & $7.51^{\mathrm{Bd}}$ & $31.49^{\mathrm{Ae}}$ & $24.35^{\mathrm{Be}}$ & $52.67^{\mathrm{Aa}}$ & $55.85^{\mathrm{Aa}}$ \\
\hline 与密度的 $r$ & 0.5539 & -0.2781 & $-0.9702^{*}$ & $-0.9809^{*}$ & $0.9889^{*}$ & $0.9937^{*}$ \\
\hline
\end{tabular}

$P S D$ : Plant seedling density $\quad$ M-N : Middle-N $\quad$ H-N :High-N PHMR : Percentage of head milled rice PCR : Percentage of chalky rice

每列中的大写字母表示同一性状在同一密度条件下不同施氮量间的 LSD 比较 , 小写字母表示同一性状在同一施氮量条件下不同密度间 的 LSD 比较 The same capital letters in the same plant seedling density for the same trait among different level of $\mathrm{N}$ applied and the same lowercase in the same level of $\mathrm{N}$ applied for the same traits among different plant seedling density indicate no difference at 0.05 level 
表 2 栽秧密度对水稻植株性状的影响

Table 2 Effect of plant seedling density on the traits of rice plant

\begin{tabular}{|c|c|c|c|c|c|c|c|c|c|c|}
\hline $\begin{array}{c}\text { 施氮水平 } \\
\text { LNA }\end{array}$ & $\begin{array}{c}\text { 密度 } \\
\text { Density } \\
\left(10^{4} \text { hill }\right. \\
\left.\mathrm{hm}^{-2}\right)\end{array}$ & $\begin{array}{c}\text { 成穗率 } \\
P E \\
(\%)\end{array}$ & $\begin{array}{c}\text { 有效穗 } \\
P P \\
\left(10^{4} \mathrm{hm}^{-2}\right)\end{array}$ & $\begin{array}{c}\text { 着粒数 } \\
\text { (粒/穗) } \\
G P\end{array}$ & $\begin{array}{c}\text { 结实率 } \\
\text { SSR } \\
(\%)\end{array}$ & $\begin{array}{c}\text { 千粒重 } \\
1 G W \\
(\mathrm{~g})\end{array}$ & $\begin{array}{c}\text { 库容量 } \\
\text { Sink } \\
\left(10^{4} \text { grain }\right. \\
\left.\mathrm{m}^{-2}\right)\end{array}$ & $\begin{array}{c}\text { 籽粒容重 } \\
G U \\
\left(\mathrm{mg} \mathrm{ml}{ }^{-1}\right)\end{array}$ & $\begin{array}{c}\text { 叶粒比 } \\
R L G \\
\left(\mathrm{mg} \text { grain }^{-1}\right)\end{array}$ & $\begin{array}{c}\text { 灌浆速率 } \\
\text { GFR } \\
\left(\mathrm{mg} \text { grain }^{-1}\right. \\
\left.\cdot \mathrm{d}^{-1}\right)\end{array}$ \\
\hline \multirow{6}{*}{$\mathrm{H}-\mathrm{N}$} & 4.83 & 86.09 & 174.60 & 189.39 & 75.75 & 27.28 & 33.07 & 1.31 & 6.29 & 1.06 \\
\hline & 7.51 & 73.75 & 210.30 & 179.32 & 78.23 & 27.64 & 37.71 & 1.28 & 6.48 & 1.10 \\
\hline & 10.76 & 67.46 & 232.65 & 158.23 & 81.24 & 27.62 & 36.81 & 1.21 & 7.13 & 1.19 \\
\hline & 14.80 & 65.01 & 255.00 & 142.94 & 86.54 & 27.71 & 36.45 & 1.12 & 7.60 & 1.23 \\
\hline & 18.91 & 59.57 & 257.25 & 135.45 & 86.27 & 27.19 & 34.84 & 1.06 & 8.05 & 1.28 \\
\hline & 21.64 & 57.72 & 261.75 & 114.49 & 88.78 & 27.13 & 29.97 & 1.03 & 8.82 & 1.36 \\
\hline \multicolumn{2}{|c|}{$\begin{array}{c}\text { 与密度的 } r \\
r \text { with PSD }\end{array}$} & $-0.941^{*}$ & $0.926^{*}$ & $-0.988^{*}$ & $0.970^{*}$ & -0.465 & -0.475 & $-0.995^{*}$ & $0.989^{*}$ & $0.989^{*}$ \\
\hline \multirow{6}{*}{$\mathrm{M}-\mathrm{N}$} & 4.83 & 88.13 & 172.95 & 187.60 & 78.81 & 27.16 & 32.45 & 1.29 & 6.04 & 1.04 \\
\hline & 7.51 & 79.09 & 207.50 & 178.84 & 80.60 & 27.48 & 37.16 & 1.27 & 6.21 & 1.09 \\
\hline & 10.76 & 76.94 & 220.65 & 164.05 & 85.87 & 27.34 & 36.20 & 1.22 & 6.95 & 1.16 \\
\hline & 14.80 & 66.28 & 231.30 & 156.90 & 89.97 & 27.25 & 36.29 & 1.14 & 7.28 & 1.25 \\
\hline & 18.91 & 63.75 & 240.55 & 150.12 & 88.04 & 27.48 & 36.11 & 1.09 & 7.72 & 1.29 \\
\hline & 21.64 & 56.94 & 249.80 & 125.75 & 88.81 & 27.75 & 31.41 & 1.02 & 8.54 & 1.31 \\
\hline \multicolumn{2}{|c|}{$\begin{array}{c}\text { 与密度的 } r \\
r \text { with PSD }\end{array}$} & $-0.984^{*}$ & $0.939^{*}$ & $-0.973^{*}$ & $0.881^{*}$ & 0.718 & -0.209 & $-0.994^{*}$ & $0.985^{*}$ & $0.984^{*}$ \\
\hline
\end{tabular}

LNA :Level of $\mathrm{N}$ applied $P E:$ Percentage of productive panicle $P P$ : Productive panicle $\quad G P:$ Grain per panicle $S S R$ : Seed setting rate $\quad$ IGW : 1000 grain weight $G U:$ Grain unit $R L G$ : Ratio of leaf to grain $G F R$ : Grain filling rate

$\mathrm{H}-\mathrm{N}$,M-N ,PSD :同表 1 See Table1

$-0.9567^{* *}$ ),又降低了叶粒比(表 2 )。二者是否都 对提高米质有作用呢? 从试验结果表 3 可见 :1)处 理 I 齐穗期的叶粒比和透光率比处理 II 明显降低, 其整精米率和严白粒率得到显著改善。2)处理 II 齐穗期的叶粒比与 CK 差异不显著, 虽然其透光率 比对照显著提高, 但二者的整精米率和严白粒率差 异并不显著。以上结果两个组合的表现一致, 说明 水稻灌浆期群体光照条件的改善对提高整精米率和 降低严白粒率作用不明显，处理 I 比处理 II 整精米 率和严白粒率得到显著改善应该是降低了齐穗期群 体叶粒比起作用的结果。追究齐穗期群体叶粒比影 响整精米率和严白粒率原因, 随着本田栽种密度的 降低，每穗着粒数则增加，单位颖花的源占有量(叶 粒比)则减少(表 2)。单位颖花的源占有量越少, 稻 穗籽粒灌浆速率越慢, 籽粒容重越高; 籽粒容重高, 表明淀粉粒间空隙越小, 加工时的抗折力越强 (沈 波 2000) , 以致整精米率与籽粒容重呈极显著正相 关, 籽粒灌浆速率越快, 淀粉粒间空隙越大, 稻米严 白面积也越大(沈波 2000), 因此严白粒率与灌浆速 率呈极显著正相关关系(表 4)。这就是通过水稻超 稀植影响源库结构近而提高整精米率和降低严白粒 率的原因所在。

\section{3 灌浆期施氮对结实率、整精米率的影响}

前已述及, 水稻实行超稀栽培后, 虽然其整精米
率和严白粒率改善了, 但因穗子变大 结实率明显下 降，对其高产潜力的发挥有一定影响 (表 2)。为此, 特开展了齐穗后不同时期施氮对结实率和米质影响 的研究。试验结果 (表 5) 表明, 齐穗后不同时期施 氮对产量、结实率和整精米率影响显著，对千粒重和 严白粒率的影响未达显著水平。其中, 齐穗后 $0 、 10$ $\mathrm{d}$ 施氮两个处理的产量和结实率均比对照显著提 高, 但整精米率却比对照显著降低; 济穗后 $20 \mathrm{~d}$ 施 氮处理的产量、结实率均比对照显著提高 整精米率 与对照相当; 齐穗后 $30 \mathrm{~d}$ 施氮处理的产量、结实率 和整精米率均与对照差异不显著。以上说明以齐穗 后 $20 \mathrm{~d}$ 左右施氮为佳。究其原因, 施氮后提高了叶 片全氮含量及其光合速率, 灌浆速率也明显提高，从 而有利于籽粒灌浆结实( 凌启鸿等 1995 ; 蒋彭炎等, 1994 , 徐富贤等, 1997)。因此, 齐穗后 0、10、20 d 3 个 时期施氮的结实率和产量都得到显著提高, 齐穗后 $30 \mathrm{~d}$ 施氮处理因施肥时期太迟 (仅距成熟期 $5 \mathrm{~d}$ 左 右)而无作用。由于稻米整精米率主要受齐穗后 0 $\sim 20 \mathrm{~d}$ 时段的灌浆速率的影响, 齐穗 $20 \mathrm{~d}$ 以后的灌 浆速率对整精米率的影响不显著(徐富贤等, 2003b), 以致齐穗后 $0 、 10 \mathrm{~d}$ 施氮两处理的整精米率 比对照显著降低, 而齐穗后 $20 \mathrm{~d}$ 施氮处理则无明显 影响。以上结果两个杂交组合均表现一致。 
表 3 齐穗期叶粒比与透光率对整精米率和严白粒率的影响

Table 3 Effect of the leaf to grain ratio and the light transmission at full heading on the percentage of head milled rice and chalky rice

\begin{tabular}{|c|c|c|c|c|c|c|c|c|}
\hline \multirow[b]{2}{*}{ 处理 } & \multicolumn{4}{|c|}{ 汕优 63”' Shanyou 63’ } & \multicolumn{4}{|c|}{ 香优 2 号”' Xiangyou 2’ } \\
\hline & 叶粒比 & 透光率 & 整精米率 & 严白粒率 & 叶粒比 & 透光率 & 整精米率 & 严白粒率 \\
\hline Treatment & $\begin{array}{c}R L G \\
\left(\mathrm{mg} \operatorname{grain}^{-1}\right)\end{array}$ & $\begin{array}{c}L T \\
(\%)\end{array}$ & $\begin{array}{c}\text { PHMR } \\
(\%)\end{array}$ & $\begin{array}{l}P C R \\
(\%)\end{array}$ & $\begin{array}{c}\text { RLG } \\
\left(\mathrm{mg} \mathrm{grain}^{-1}\right)\end{array}$ & $\begin{array}{l}\text { LT } \\
(\%)\end{array}$ & $\begin{array}{c}\text { PHMR } \\
(\%)\end{array}$ & $\begin{array}{l}\text { PCR } \\
(\%)\end{array}$ \\
\hline I & $6.81^{\mathrm{B}}$ & $8.43^{\mathrm{B}}$ & $48.14^{\mathrm{A}}$ & $39.67^{\mathrm{B}}$ & $6.42^{\mathrm{B}}$ & $9.27^{\mathrm{B}}$ & $51.76^{\mathrm{A}}$ & $21.08^{\mathrm{B}}$ \\
\hline II & $8.27^{\mathrm{A}}$ & $15.31^{\mathrm{A}}$ & $34.87^{\mathrm{B}}$ & $51.19^{A}$ & $8.15^{\mathrm{A}}$ & $16.75^{\mathrm{A}}$ & $39.64^{\mathrm{B}}$ & $39.77^{\mathrm{A}}$ \\
\hline CK & $8.21^{\mathrm{A}}$ & $3.86^{\mathrm{C}}$ & $31.14^{\mathrm{B}}$ & $48.90^{\mathrm{A}}$ & $8.07^{\mathrm{A}}$ & $3.94^{\mathrm{C}}$ & $36.69^{\mathrm{B}}$ & $36.06^{\mathrm{A}}$ \\
\hline
\end{tabular}

I : 每公顷栽 9 万穴 $9 \times 10^{4}$ hill $\mathrm{hm}^{-2}$ for plant seedling density II :齐穗期将每公顷栽 18 万穴改变为 9 万穴 The plant seedling density at full

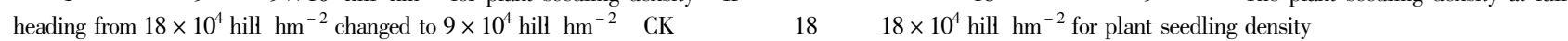
同字母表示在 0.01 水平差异不显著 The same letters in the same column indicate no difference at 0.01 level $\quad L T$ : Light transmission $\quad P H M A$,PCR :同表 1 See Table $1 \quad R L G$ :同表 2 See Table 2

表 4 水稻植株主要性状与整精米率和严白粒率间的相关分析

Table 4 Correlation analysis between main traits of rice plant and percentage of head milled rice and chalky rice

\begin{tabular}{|c|c|c|c|}
\hline \multirow[b]{2}{*}{$y$} & \multirow{2}{*}{$x$} & \multicolumn{2}{|c|}{$r$} \\
\hline & & H-N & M-N \\
\hline 灌浆速率 GFR & 叶粒比 $R L G$ & $0.9950^{*}$ & $0.9556^{*}$ \\
\hline 籽粒容重 $G U$ & 灌浆速率 GFR & $-0.9801^{*}$ & $-0.9713^{*}$ \\
\hline 整精米率 $P H M R$ & 籽粒容重 $G U$ & $0.9765^{*}$ & $0.9744^{*}$ \\
\hline 普白粒率 $P C R$ & 灌浆速率 GFR & $0.9892^{*}$ & $0.9736^{*}$ \\
\hline 整精米率 $P H M R$ & 垩白粒率 $P C R$ & $-0.9817^{*}$ & $-0.9711^{*}$ \\
\hline
\end{tabular}

H-N ,M-N ,PHMR ,PCR :同表 1 See Table 1 GFR ,GU, RLG :同表 2 See Table 2

表 5 齐穗后不同时期施氮对结实率、整精米率等性状的影响

Table 5 Effect of $\mathrm{N}$ applied at different date after full heading on seed setting rate, percentage of head milled rice $e t$ al.

\begin{tabular}{|c|c|c|c|c|c|c|c|c|c|c|}
\hline \multirow[b]{2}{*}{$\begin{array}{c}\text { 施氮时期 } \\
\text { NAD } \\
(\mathrm{DFH})\end{array}$} & \multicolumn{5}{|c|}{ ' 汕优 63' Shan you 63’ } & \multicolumn{5}{|c|}{ “香优 2 号”' Xiang you 63’ } \\
\hline & $\begin{array}{c}\text { 结实率 } \\
\text { SSR } \\
(\%)\end{array}$ & $\begin{array}{c}\text { 千粒重 } \\
1 G W \\
(\mathrm{~g}) \\
\end{array}$ & $\begin{array}{c}\text { 整精米率 } \\
\text { PHMR } \\
(\%)\end{array}$ & $\begin{array}{c}\text { 垩白粒率 } \\
P C R \\
(\%)\end{array}$ & $\begin{array}{cc} & \text { 产量 } \\
& G Y \\
(\mathrm{t} & \left.\mathrm{hm}^{-2}\right) \\
\end{array}$ & $\begin{array}{c}\text { 结实率 } \\
\text { SSR } \\
(\%)\end{array}$ & $\begin{array}{c}\text { 千粒重 } \\
1 G W \\
(\mathrm{~g}) \\
\end{array}$ & $\begin{array}{c}\text { 整精米率 } \\
\text { PHMR } \\
(\%)\end{array}$ & $\begin{array}{c}\text { 垩白粒率 } \\
P C R \\
(\%)\end{array}$ & $\begin{array}{cc} & \text { 产量 } \\
& G Y \\
(\mathrm{t} & \left.\mathrm{hm}^{-2}\right) \\
\end{array}$ \\
\hline 0 & $88.05^{\mathrm{a}}$ & $28.91^{\mathrm{a}}$ & $42.32^{\mathrm{b}}$ & $46.30^{\mathrm{a}}$ & $9.05^{\mathrm{a}}$ & $86.72^{\mathrm{a}}$ & $27.18^{\mathrm{a}}$ & $46.26^{\mathrm{b}}$ & $26.61^{\mathrm{a}}$ & $9.18^{\mathrm{a}}$ \\
\hline 10 & $87.78^{\mathrm{a}}$ & $28.82^{\mathrm{a}}$ & $41.66^{\mathrm{b}}$ & $47.52^{\mathrm{a}}$ & $9.08^{\mathrm{a}}$ & $86.96^{\mathrm{a}}$ & $27.56^{\mathrm{a}}$ & $47.30^{\mathrm{b}}$ & $26.00^{\mathrm{a}}$ & $9.12^{\mathrm{a}}$ \\
\hline 20 & $87.93^{\mathrm{a}}$ & $28.90^{\mathrm{a}}$ & $46.70^{\mathrm{a}}$ & $48.01^{\mathrm{a}}$ & $9.07^{\mathrm{a}}$ & $86.88^{\mathrm{a}}$ & $27.30^{\mathrm{a}}$ & $53.78^{\mathrm{a}}$ & $27.82^{\mathrm{a}}$ & $9.14^{\mathrm{a}}$ \\
\hline 30 & $83.35^{b}$ & $28.76^{\mathrm{a}}$ & $46.78^{\mathrm{a}}$ & $46.87^{\mathrm{a}}$ & $8.71^{\mathrm{b}}$ & $80.05^{\mathrm{b}}$ & $27.23^{\mathrm{a}}$ & $54.15^{\mathrm{a}}$ & $25.36^{\mathrm{a}}$ & $8.65^{\mathrm{b}}$ \\
\hline CK (NNA) & $83.62^{\mathrm{b}}$ & $28.71^{\mathrm{a}}$ & $47.50^{\mathrm{a}}$ & $44.39^{\mathrm{a}}$ & $8.64^{\mathrm{b}}$ & $79.63^{\mathrm{b}}$ & $27.04^{\mathrm{a}}$ & $54.34^{\mathrm{a}}$ & $24.63^{\mathrm{a}}$ & $8.59^{\mathrm{b}}$ \\
\hline
\end{tabular}

同一列数据后跟有相同字母表示在 0.05 水平差异不显著 The same letters in the same column indicate no difference at 0.05 level $N A D: \mathrm{N}$ applied date $\quad G Y$ : Grain yield $D F H$ : 齐穗后日数 Day after full heading $N N A$ : 不施氮 No N applied

\section{3 讨 论}

关于本田栽培密度对稻米品质的影响, 较多学 者认为 稀植有利于提高出粘率、精米率、整精米率 和透明度(徐富贤等,1994;徐富贤等,2003a) ,但其 米质的提高程度并非十分理想(徐富贤等,2003a)。 本试验结果表明，无论是中氮还是高氮施肥水平，当 栽秧密度超稀到 7.51 万穴 $\mathrm{hm}^{-2}$ 时, 在保证比传统 高产栽培密度每公顷栽秧 21.64 万穴的对照不减产 前提下, 整精米率提高了 $15.69 \%$ 29.92\% 严白粒 率降低了 $16.34 \% \sim 21.22 \%$ (表 1), 具有十分显著 地提高整精米率和降低严白粒率的效应。其原因在 于, 超稀植大大增加了每穗着粒数, 降低了齐穗期的 叶粒比, 以致稻穗籽粒灌浆速率减慢, 籽粒容重增加 而提高整精米率。同时因籽粒灌浆速率减慢, 淀粉 粒间空隙也减小, 稻米严白面积也随之减小 (沈波
等 2000）,使严白粒率与灌浆速率呈极显著正相关 关系(表 2 ,表 4)。这就启示我们, 目前四川省正大 力开展的水稻强化栽培 (超稀植是其主要特点之一) 的研究与示范, 不仅是实现水稻超高产的一条有效 途径, 而且对提高稻米品质也有十分重要的作用。

超稀栽培改善稻米品质的作用程度在地区间有 较大差异。如本试验所在地泸州市因水稻灌浆期气 温较高, 以致籽粒灌浆速率加快而大大地降低了整 精米率和增加了严白粒率(徐富贤等 ,1994; 徐富贤 等 2003b) 超稀栽培正是通过降低齐穗期叶粒比以 减慢了稻穗籽粒灌浆速率, 起到了对症下药的作用 而收到了奇效。但水稻籽粒灌浆期的气温已非常适 合优质米形成的成都市, 超稀栽培虽然也有明显改 善稻米整精米率与严白性状的作用, 但在程度上却 明显比沪州小(徐富贤等,2003a)。说明超稀栽培对 提高稻米品质的作用程度可能与稻穗籽粒灌浆期的 
气温状况有密切关系, 尚需进一步开展这方面的研 究工作。同时也应注意到, 因稀植的灌浆速率减慢， 较优的稀植处理 (7.51 万穴 $\mathrm{hm}^{-2}$ ) 灌浆期相应延长 了 3 天左右, 若要蓄再生稻且热量条件稍差的地区, 应选择全生育期短 $2 \sim 3$ 天的组合为宜, 以确保再生 稻的安全开花受精。此外，稀植的程度也对米质有 显著影响，如四川省杂交中稻现行高产栽培法一般 为每公顷栽 22.50 万穴左右, 稀植的也在 13.5 万穴 $\mathrm{hm}^{-2}$ 左右(杨泽敏等, 2001) ,与本试验的研究结果 超稀栽培每公顷栽 7.5 万穴相比也显得较密。分析 其因, 以前研究水稻的高产栽培密度时在设计上存 在保守思想,一般其最稀试验处理也在 12 万穴 $\mathrm{hm}^{-2}$ 左右，根本没有考虑到进一步稀植也会高产和 提高米质的问题。由此可见，以前研究稀植对提高 米质的效果不如本研究, 可能与先期研究的试验设 计的稀植程度不够有关。

本试验结果表明, 水稻实行超稀栽培后, 虽然其 整精米率和严白粒率改善了, 但因穗子变大 结实率 明显下降，对其高产潜力的发挥有一定影响 (表 2)。 凌启鸿等 (1995)、蒋彭炎等 (1994) 主张在齐穗期施 粒肥以提高结实率和千粒重。从本研究结果看, 虽 然齐穗期施粒肥可显著提高结实率而增产, 但也因 同时提高了穗部籽粒的灌浆速率而降低整精米率， 在齐穗后 20 天施氮可同时起到提高结实率和整精 米率的双重效果 (表 5) ,而且也与再生稻促芽肥的 施用时期相符(徐富贤等,1997)。因此,在超稀栽培 情况下, 杂交中稻粒肥的施用时期应改在齐穗后第 二十天左右施用为佳, 此时施肥既有利于头季中稻 高产与优质，又可同时起到再生稻促芽肥的作用。

\section{参 考 文 献}

Hu, B. M. (胡秉民) \& Q. D. Zhang (张全德). 1985. Method of statistics analysis for agricultural experiment. Hangzhou: Zhejing Science Technology Press. 72 240. (in Chinese)

Jiang, P. Y. (蒋彭炎) ,X. F. Hong(洪晓富) \& L. D. Feng (冯 来定) . 1994. Relationship between percentage of ear-bearing of colony in the middle phase and photosynthesis efficiency in the late in rice. Scientia Agricultura Sinica(中国农业科学), 276: $8 \sim 14$. (in Chinese with English abstract)

Liao, F. M. (廖伏明), K. L. Zhou(周坤炉) \& H. H. Yang(阳 和华). 1999. Study on the rice quality of three-line indica hybrid rice. Hybrid Rice(杂交水稻), 146:35 38. (in Chinese with English abstract)

Ling, Q. H. (凌启鸿), Z.F. Su(苏祖芳) \& H. Q. Zhang(张 海泉). 1995. Studies on relationship between the population quality in the late stage and percentage of ear-bearing and their effect factors in rice plant. Acta Agronomica Sinica(作物学报), 214:463 469. (in Chinese with English abstract)

Quality and Technology Control Bureau of China(国家质量技术监 督局).1999. Nation quality standards for main grain crop (GB/ T $17891-1999$ ), www. ccvi. net: $1 \sim 11$. (in Chinese)

Shen, B. (沈波).2000. Rservation on the starch development in endosperm of early indica rice during chalkiness formation with scanning electronic microscope. Chinese Journal of Rice Science (中国水稻科学), 144: 225 228. (in Chinese with English abstract)

Xu，F. X. (徐富贤) \& S. Hong (洪 松). 1994. Review on effect of environmental factors on rice quality. Southwest China Journal of Agricultural Sciences (西南农业学报), 72: 101 105. (in Chinese with English abstract)

Xu, F. X. (徐富贤), S. Hong (洪松) \& H. Xiong(熊洪). 1997. Relationship between N applying for bud development and ratooning ability and its mechanism in hybrid rice. Acta Agronomica Sinica(作物学报), 233:311 317. (in Chinese with English abstract)

Xu，F.X.(徐富贤)，H. Xiong(熊 洪)，Y. C. Zhu(朱永川) \& G.X. Wang (王贵雄). 2003a. Study on cultivation of high yield and good quality for Fei-You 1, Hybrid mid-season rice, in ratooning rice of south-area of Sichuan. Science and Technology of Sichuan Agriculture (四川农业科技), 2: 18 21. (in Chinese)

Xu，F. X. (徐富贤), J. K. Zheng(郑家奎) Y. C. Zhu (朱永 川) \& G.X. Wang(王贵雄).2003b. Effect of atmospheric phenomena factors on the milling quality and the appearance quality of medium India hybrid rice during the period from full heading to maturity. Acta Phytoecologica Sinica (植物生态学报), 271:73 $\sim 77$. (in Chinese with English abstract)

Yang, Z. M. (杨泽敏), W.J. Wang (王维金) \& S. M. Xu(徐水 明). 2001. Effects of area solution applied at leaves on filling characters and quality of rice at flowering and filling period. Reclaiming and Rice Cultivation(良殖与稻作), 3:20 22, 43 . (in Chinese)

Zhu, Y. C. (朱永川)，F。 X. Xu(徐富贤), J. K. Zheng(郑家 奎) \& G.X. Wang (王贵雄). 2000. The appearance quality of good quality rice of Sichuan Province. China Rice(中国稻米), 2:33 34. (in Chinese) 